\title{
Study of pattern of congenital anomalies at tertiary center in Maharashtra, India
}

\author{
B. B. Yadav*, S. B. Yadav, P. K. Damase
}

Department of Obstetrics and Gynaecology, Government Medical college, Latur, Maharashtra, India

Received: 08 May 2018

Accepted: 01 June 2018

*Correspondence:

Dr. B.B.Yadav,

E-mail: drshriyadav@yahoo.co.in

Copyright: (C) the author(s), publisher and licensee Medip Academy. This is an open-access article distributed under the terms of the Creative Commons Attribution Non-Commercial License, which permits unrestricted non-commercial use, distribution, and reproduction in any medium, provided the original work is properly cited.

\begin{abstract}
Background: To highlight common pattern of congenital malformation seen at hospital population of tertiary care center in Maharashtra.

Methods: The study was a descriptive prospective study and conducted in the department of obstetrics and gynaecology of government medical college Latur, Maharashtra for a period of six months. Study includes all womens coming for 2nd trimester MTP due to congenital anomalies in foetus and women's admitted in labour having anomalous foetus. Details of maternal age, parity, type of anomaly present and sex of fetus were noted.

Results: Total babies born in the study period were 3482 (including the second trimester abortions). Total babies with congenital abnormality were 75 , making the prevalence $2.15 \%$. 10 cases (13.33) had multiple anomalies involving more than one system. The predominant system involved was central nervous system 40 (53.33\%) followed by gastrointestinal system 15 (20\%). In this study male babies affected more than females.

Conclusions: Prevalence of the congenital anomalies will be definitely higher at tertiary care center and to know prevalence in community, more community based studies are required. Increased awareness about preventable risk factors may help in reducing the incidence of congenital anomalies.
\end{abstract}

Keywords: Anomalies, Consanguinity, Neonates, Prevalence

\section{INTRODUCTION}

Congenital anomaly may be narrowly defined in terms of physical structure as a malformation or more widely as to include functional disturbance as a defect, any irreversible condition existing in a child before birth in which there is sufficient deviation in usual number, size, shape, location or inherent character of any part, organ, cell or cell constituent to warrant its designation as abnormal. In short its any alteration present at birth of normal anatomic structure and has cosmetic, medical or surgical significance. ${ }^{1}$ Early recognition of anomalies is important for planning care, with some such as tracheoesophageal fistula, diaphragmatic hernia, choanal atresia and intestinal obstruction, immediate medical and surgical therapy is essential. ${ }^{2}$ The worldwide incidence of congenital disorder is estimated at $3-7 \%$, but actual numbers vary widely between countries. ${ }^{3,4}$

The inability to discover the causes of congenital malformations is one of the most miserable failures of modern medicine. The problem has been described as 'an epidemiologist's nightmare.

While much progress has been made in early detection of congenital malformations, the area of etiopathogenesis is still shrouded with darkness. Genetics, drugs, viruses and environment all have a role in causation but for vast majority of malformations the exact cause is not known. Thus it may not always be possible to prevent congenital 
malformations but mortality and morbidity secondary to these can be reduced by early detection and proper management. Prenatal diagnosis is possible in $2^{\text {nd }}$ trimester on maternal ultrasonography.

Awareness of local prevalence and pattern of malformations with associated factors in mother if any can help the doctors rendering medical care to identify 'at risk' cases early, and plan appropriate and effective intervention. The present study is an effort in this direction.

\section{METHODS}

The study was a descriptive prospective study and conducted in the department of obstetrics and gynaecology of government medical college latur, Maharashtra. Approval was taken from the Hospital Ethical Committee. Verbal consent was taken from all the mothers recruited into the study.

Study includes all women's coming for $2^{\text {nd }}$ trimester MTP due to congenital anomalies in foetus and women's admitted in labour having anomalous foetus. All the fetuses induced following detection by ultrasound and those babies detected to have congenital anomalies by postnatal examination were included in the study.

All the live born, still born, intrauterine deaths and neonatal deaths were included in the study

Demographic characteristics of mothers, consanguinity, parity, gestational age, mode of delivery, type of congenital anomaly and sex of fetus were recorded in a preplanned Performa. All live neonates were examined thoroughly by pediatricians and confirmation of internal defects was done by various imaging modalities.

The results were analyzed by simple statistical techniques.

\section{RESULTS}

Total babies born in the study period were 3482 (including the second trimester abortions). Total babies with congenital abnormality were 75 (2.15\%).

Table 1: Parity wise anomalies.

\begin{tabular}{|lcc|}
\hline Parity & No. of cases & Percentage \\
\hline Primi & 25 & $33.33 \%$ \\
\hline G2 & 28 & $37.33 \%$ \\
\hline G3 & 16 & $21.33 \%$ \\
\hline G4 & 5 & $6.66 \%$ \\
\hline
\end{tabular}

Demographic profile of the patients with fetus having congenital anomalies shown in the tables. In this study babies born to $2^{\text {nd }}$ gravid mothers has significantly higher incidence of malformations fallowed by primigravida.
Incidence of congenital anomaly was the least in $4^{\text {th }}$ gravid.

Table 2: Anomalies and maternal age.

\begin{tabular}{|lll|}
\hline Age group & No. of cases & Percentage \\
\hline$<20$ years & 18 & $24 \%$ \\
\hline $21-25$ years & 39 & $52 \%$ \\
\hline $26-30$ years & 15 & $20 \%$ \\
\hline $30-35$ years & 2 & $2.66 \%$ \\
\hline $36-40$ years & 1 & $1.33 \%$ \\
\hline
\end{tabular}

Maternal age was divided in to 5 groups, 18 (24\%) fell in to age group of $<20$ years, $39(52 \%)$ fell in to $21-25$ years age range, $15(20 \%)$ fell in to 26-30 years age group and $3(3.99 \%)$ were greater than 30 years of age.

Congenital anomalies were commonly seen in 21-25 years age group. In this study incidence of anomalies is less i.e. $2.66 \%$ and $1.33 \%$ in the age group $30-35$ years and 36-40 years respectively.

Table 3: Gender and anomalies.

\begin{tabular}{|lll|}
\hline Sex & No. of cases & Percentage \\
\hline M & 41 & $54.66 \%$ \\
\hline F & 34 & $45.66 \%$ \\
\hline
\end{tabular}

Among all the babies, $54.66 \%$ were males and $45.66 \%$ were females. Congenital anomalies seen in higher percentage in male group.

Table 4: Pattern of anomalies observed.

\begin{tabular}{|l|ll|}
\hline System affected & No. of cases & Percentage \\
\hline CNS & 40 & $53.33 \%$ \\
\hline GIT & 15 & $20 \%$ \\
\hline Musculoskeletal & 12 & $16 \%$ \\
\hline CVS & 8 & $10.66 \%$ \\
\hline GU System & 8 & $10.66 \%$ \\
\hline miscellaneous & 2 & $2.66 \%$ \\
\hline
\end{tabular}

Central nervous system was the most commonly affected system $40(53.33 \%)$ followed by gastrointestinal system 15 (20\%), musculoskeletal system 12 (16\%), cardiovascular and genitourinary system each with 8 $(10.66 \%)$ and miscellaneous $2(2.66 \%)$.

Of 75 cases $65(86.66 \%)$ had involvement of single system and $10(13.33 \%)$ had involvement of more than one system.

Table 5: Number of system affected.

\begin{tabular}{|lll|}
\hline System & No. of cases & Percentage \\
\hline Single & 65 & $86.66 \%$ \\
\hline Multiple & 10 & $13.33 \%$ \\
\hline
\end{tabular}




\section{DISCUSSION}

This study was done to find out the incidence of congenital anomalies in a tertiary care center in Maharashtra.

The pattern and prevalence may vary over time and with geographical location and there are no reliable estimates of the number of children who were born with a serious congenital disorder due to genetic or environmental causes. The incidence of congenital anomalies in our hospital study of six months was $2.15 \%$. Incidence might be higher in our study because this is a government tertiary center and we got referrals for $2^{\text {nd }}$ trimester abortion due to anomalies. These findings are comparable to similar studies from India, which reported an incidence of $2.72 \%$ and $1.9 \%, 2.48 \% .^{8-10}$

The most common anomaly detected was Central nervous system malformations, 40/75 (53.33\%). Many studies have shown that CNS malformations were associated with high perinatal mortality. ${ }^{11}$ Gastrointestinal tract malformations were found in $15 / 75$ (20\%) cases. Genitourinary system and cardiovascular system malformations were found in 8 cases each (10 .66\%).

Incidence of Cardiac anomalies in our study is comparable to studies conducted in JIPMER, Pondicherry. ${ }^{12}$ Males were more affected in the study which was similar to other studies. ${ }^{13}$ In this study multiple system involved in $13.33 \%$ cases. Mishra and Bhaveja found multiple anomalies in $37.6 \%$ of cases and Swain $\mathrm{S}$ et al reported multiple anomalies in $18.8 \%$ of babies.

The study found that congenital anomalies were more in babies of consanguineous marriage. This is similar to several previous studies. ${ }^{4,14}$ It is important to increase awareness about the consequences of consanguineous marriages. Women in reproductive age group should be counseled about the benefits of folic acid supplementation especially preconceptional in the high risk group. Rubella vaccination should be recommended for adolescent girls.

\section{CONCLUSION}

Of the 3482 consecutive deliveries 75 had congenital anomalies giving overall incidence of $2.154 \%$. The study found that congenital anomalies were more in babies of consanguineous marriages. Efforts should be taken to avoid consanguineous marriages in the society. Preconception counseling and supplementation of folic acid done in high risk group for prevention of neural tube defects. Anomalies scan by ultrasound at 18-20 weeks will exclude majority anomalies. Prevalence of the congenital anomalies will be definitely higher at tertiary care center and to know prevalence in community, more community based studies are required.

Funding: No funding sources

Conflict of interest: None declared

Ethical approval: The study was approved by the Institutional Ethics Committee

\section{REFERENCES}

1. Padubidri V, Anand E, Textbook of obstetrics, BI publications Delhi; 2006:462. ISBN:81-7225-223-4.

2. World health organization, sixty third world health assembly, birth defects . 2010;A63:10-2.

3. Howson CP, Christianson AC, Modell B-Controlling birth defects: reducing the hidden toll of dying and disabled children in low-income countries. Dis Control Prior Proj. 2008.

4. Singh A, Gupta RK. Pattern of congenital anomalies in newborn: a hospital based prospective study. JK Sci. 2009;1:34-6.

5. Bhat BV, Ravikumara M. Perinatal mortality in India-Need for introspection. Indian J Matern Child Health. 1996;7:31-3.

6. Agarwal SS, Singh U, Singh PS, Singh SS, Das V, Sharma A, et al. Prevalence and spectrum of congenital malformations in a prospective study at a teaching hospital. Indian J Med Res. 1991;94:413-9.

7. Parmar A, Rathod SP, Patel SV, Patel SM. A study of congenital anomalies in newborn. NIJRM. 2010;1:13.

8. Chaturvedi P, Banerjee KS. Spectrum of congenital malformations in Newborns from rural Maharashtra. Indian J Pediatr. 1989;56:501-7.

9. Taksande A, Vilhekar K, Chaturvedi P, Jain M. Congenital malformations at birth in Central India: A rural medical college Hospital based data. Indian $\mathbf{J}$ Hum Genet. 2010;16(3):159-63.

10. Vinod SL, Balakrishnan. Pattern of congenital anomalies in a Tertiary care center. JMSCR. 2017;5:1.

11. Shah D. A FOGSI report on perinatal audit1999, data related to perinatal deaths from 64 centers in India, oct.95 to oct.98.

12. Bhat VB, Babu L.Congenital malformations at birthA prospective study from south India. Indian $\mathbf{J}$ Pediatr. 1998;65:873-81.

13. Mohanty C, Mishra OP, Das BK, Bhatia BD, Singh G. Congenital malformations In newborns: A study of 10,874 consecutive births. J Anat Soc India. 1989;38:101-11.

14. Swain S, Agrawal A, Bhatia BD. Congenital malformations at birth. Indian Pediatr. 1994;31:1187-91.

Cite this article as: Yadav BB, Yadav SB, Damase PK. Study of pattern of congenital anomalies at tertiary center in Maharashtra, India. Int J Reprod Contracept Obstet Gynecol 2018;7:2802-4. 